\title{
Targeting PIK3CG in Combination with Paclitaxel as a Potential Therapeutic Regimen in Claudin-Low Breast Cancer
}

\author{
Jun Chang ${ }^{1,2}$ \\ Ling Hong ${ }^{2}$ \\ Yaozhong $\mathrm{Liu}^{3}$ \\ Yiwen $\operatorname{Pan}^{2}$ \\ Hao Yang ${ }^{2}$ \\ Wenrui $\mathrm{Ye}^{3}$ \\ Keli $\mathrm{Xu}^{4}$ \\ Zhijian $\mathrm{Li}^{\prime}$ \\ Shubing Zhang $\mathbb{D}^{1,2,5,6}$ \\ 'Department of Anesthesiology, The \\ Second Xiangya Hospital of Central South \\ University, Changsha, Hunan 4I00II. \\ People's Republic of China; ${ }^{2}$ Department of \\ Cell Biology, School of Life Sciences, \\ Central South University, Changsha, Hunan \\ 4I00I3, People's Republic of China; \\ ${ }^{3}$ Xiangya Medical School, Central South \\ University, Changsha, Hunan 4I00I3, \\ People's Republic of China; ${ }^{4}$ Cancer \\ Institute, University of Mississippi Medical \\ Center, Jackson, MS 39216, USA; ${ }^{5}$ Hunan \\ Key Laboratory of Animal Models for \\ Human Diseases, Central South University, \\ Changsha, Hunan 4I0013, People's \\ Republic of China; ${ }^{6}$ Breast Cancer \\ Research Center, School of Life Sciences, \\ Central South University, Changsha, Hunan \\ 410013, People's Republic of China
}

Correspondence: Zhijian Li

Department of Anesthesiology, The Second Xiangya Hospital of Central South University, Changsha, Hunan 4I00II,

People's Republic of China

Tel +86/37873/42/4

Email lizhijian@csu.edu.cn

Shubing Zhang

Department of Cell Biology, School of Life

Sciences, Central South University,

Changsha, Hunan 4I00I3, People's

Republic of China

$\mathrm{Tel}+861397589680$

Email shubingzhang@csu.edu.cn
This article was published in the following Dove Press journal: Cancer Management and Research

Purpose: Molecular targeting is a powerful approach for aggressive claudin-low breast cancer (CLBC). Overexpression of PI3K catalytic subunit gamma (PIK3CG) in human CLBC is offering a promising opportunity for targeted therapies. We utilized a specific inhibitor of PIK3CG combined with paclitaxel (PTX) to treat CLBC cells in vitro and in vivo.

Patients and Methods: The tumor cells growth and apoptosis in vitro were analyzed by CCK8, plate clone formation assay, tumorsphere assay, Hoechst staining and flow cytometry. The invasion and metastasis ability of tumor cells in vitro were investigated by wound healing and transwell experiments. Critical gene expression levels were checked by qRTPCR and Western blot. Xenograft models with CLBC cell lines in SCID mice were established to investigate the effect of combined drugs in vivo.

Results: We identified that PIK3CG was a potential therapeutic target for CLBC patients. Targeting PIK3CG potentiated CLBC cells growth inhibition in 2D and 3D cultures by PTX. Inhibition of PIK3CG activation could enhance CLBC cells apoptosis and migration suppression induced by PTX. Manipulating autophagy was a validated approach for the use of PIK3CG inhibitor. Using CLBC xenograft mice model, we found that CLBC tumors in vivo could be well treated by combined drugs of PIK3CG inhibitor and PTX.

Conclusion: We demonstrated that PIK3CG was a potential target for the therapy of CLBC and inhibition of PIK3CG activation could reinforce the therapeutic effect of this aggressive disease by PTX. The combined use of PIK3CG inhibitor and PTX might be a potential regimen for treating this subtype of breast cancer.

Keywords: PIK3CG, paclitaxel, claudin-low breast cancer, combined drugs, targeted therapy

\section{Introduction}

Triple negative breast cancer (TNBC) accounting for approximately $15-20 \%$ of breast carcinomas, is a subtype of breast cancers that are defined on the negative protein expression for progesterone receptor $(\mathrm{PR})$, estrogen receptor $\alpha(\mathrm{ER} \alpha)$, and human epidermal growth factor receptor 2 (HER2). ${ }^{1}$ In the clinical treatment of TNBC, hormone therapy and anti-HER2 targeted therapy are ineffective, the prognosis of surgery, radiotherapy and chemotherapy is not promising. ${ }^{2}$ At present, the 5-year survival rate of TNBC is less than $30 \%{ }^{3}$

In recent years transcriptional profiling has been used to classify breast cancers into at least five molecular subtypes (basal, claudin-low, luminal A, luminal B, and HER2-enriched). ${ }^{4}$ TNBC was mainly composed of basal-like breast cancer (BLBC, 
39-54\%) and CLBC (25-39\%). Among these, CLBC share features with mammary stem cells, enhances the expression of epithelial-mesenchymal transition (EMT) and stem cell marker molecules, while the expression of tight junction proteins Claudins and E-cadherin is decreased. ${ }^{5,6}$ Clinical data and genetically engineered mouse models have shown that CLBC is more resistant to chemotherapeutic agents and has a worse prognosis than BLBC. ${ }^{7,8}$ However, no specific targeted treatment exists for CLBC.

Paclitaxel (PTX) was commonly used as one of the firstline chemotherapy drugs that acts as microtubule-stabilizing agent, inhibiting cancer cell mitosis in TNBC. ${ }^{9,10}$ However, the drug resistance of PTX develops in breast cancer patients during the disease progression and relapse in most of the patients. ${ }^{11}$ Phosphatidylinositol 3-kinases (PI3Ks) signaling is involved in different cellular processes through the phosphorylation of lipids and proteins. ${ }^{12}$ Among the PI3K enzyme family, PIK3CG (PI3Kgamma) activity is directly regulated by $\mathrm{G} \beta \gamma$ and Ras in the $\mathrm{G}$ protein coupled receptor (GPCR) pathway. ${ }^{13}$ It has the function of regulating cellular inflammation and immunity. ${ }^{14}$ It is reported that PIK3CG is also a potential target for the treatment of a few malignant tumors such as acute lymphoblastic leukemia, medulloblastoma and Kaposi sarcoma. ${ }^{15,16}$ Previous data show that PIK3CG is highly expressed only in tissue samples and cell lines of CLBC patients. Inhibition of PIK3CG activity will reduce the migration, invasion and stemness maintenance of CLBC cells. ${ }^{17,18}$

In this study, we investigated the treatment effect of targeting PIK3CG in combination with PTX in CLBC. We also identified a potential new and easily accessible tool for an adjuvant anti-cancer activity, increase the effect of chemotherapy and reducing the risk of cancer recurrence.

\section{Materials and Methods}

\section{Patients' Data}

Human data (Table 1) were obtained from the basic diagnosis of patients from the Second Xiangya Hospital of Central South University during March 2016 to January 2019. Consent has been obtained from each patient or subject after full explanation of the purpose and nature of all procedures used. The research purposes under protocols were approved by the Ethics Committee of the State Key Laboratory of Medical Genetics, Central South University. (NO. 2016030901). Written informed consent was obtained from all patients with the Declaration of Helsinki.
Table I Demographic Characteristics of Patients

\begin{tabular}{|l|l|l|l|l|l|}
\hline Patients & Age & Tumor Size & ER & PR & AR \\
\hline 01 & 53 & $3 * 2 * 2.5$ & $90 \%+$ & $40 \%+$ & $60 \%+$ \\
02 & 51 & $1.5 * 0.6 * 0.1$ & $90 \%+$ & - & $90 \%+$ \\
03 & 64 & $3 * 2.5 * 1.8$ & $90 \%+$ & $90 \%+$ & $90 \%+$ \\
04 & 58 & $6 * 5 * 5$ & - & $20 \%+$ & $85 \%+$ \\
05 & 39 & $2 * 0.5 * 0.1$ & $90 \%+$ & $90 \%+$ & - \\
06 & 49 & $7 * 6 * 5$ & - & - & - \\
07 & 49 & $5.5 * 4 * 2$ & - & - & - \\
08 & 58 & $1.5 * 1 * 1.5$ & - & - & - \\
09 & 48 & $20 * 17 * 7$ & $90 \%+$ & $90 \%+$ & $80 \%+$ \\
10 & 44 & $5 * 3 * 2.5$ & - & $50 \%+$ & $80 \%+$ \\
11 & 60 & $1.5 * 0.8 * 0.1$ & $90 \%+$ & $40 \%+$ & $65 \%+$ \\
12 & 56 & $21 * 14 * 6$ & - & - & $10 \%+$ \\
\hline
\end{tabular}

Note: +Positive.

\section{Chemicals}

AS-605240 (Selleck, USA) was dissolved in dimethyl sulfoxide (DMSO) (Solarbio, Beijing, China) at $1 \mathrm{mM}$ and stored at $-20^{\circ} \mathrm{C}$. Paclitaxel (PTX, Selleck, USA) was dissolved in dimethyl sulfoxide (DMSO) (Solarbio, Beijing, China) at 1 $\mathrm{mM}$ and stored at $-20^{\circ} \mathrm{C}$. Dulbecco's Modified Eagle Medium/HIGH GLUCOSE (DMEM/HIGH GLUCOSE) was obtained from Hyclone (USA). Fetal bovine serum (FBS) was obtained from PAN-Biotech (GER). $100 \mathrm{U} / \mathrm{mL}$ penicillin and $100 \mu \mathrm{g} / \mathrm{mL}$ streptomycin $(\mathrm{P} / \mathrm{S})$ was obtained from Solarbio (Beijing, China). Cell Counting Kit-8 (CCK8) was obtained from YEASEN (Shangai, China). TRIzol Up Plus RNA Kit was obtained from Transgene Biotech (Beijing, China). FastQuant RT Kit and SuperReal PreMix Plus (SYBR Green) was obtained from TIANGEN (Beijing, China). Hoechst 33342 Staining Kit was obtained from Bioworld Technology (Nanjing, China). RIPA buffer was obtained from Beyotime Biotechnology (Shanghai, China). Pierce Bicinchoninic Acid (BCA) Protein Assay Kit was obtained from Dingguo changsheng biotech (Beijing, China). Efficient Chemiluminescence Kit was obtained from GENVIEW (USA). Chloroquine diphosphate (CQ) was obtained from MedChemExpress (USA).

\section{Cells}

Primary cell lines were generated in this laboratory, were maintained in DMEM containing 15\% FBS and 1\% penicillin/streptomycin at $37^{\circ} \mathrm{C}$ with $5 \% \mathrm{CO}_{2}$. MDA-MB-231 cells and MCF-7 cells were purchased from were purchased from the American Type Culture Collection (ATCC) and were maintained in DMEM containing 10\% FBS and 1\% penicillin/streptomycin at $37^{\circ} \mathrm{C}$ with $5 \% \mathrm{CO}_{2}$. 


\section{Cell Proliferation}

Human breast cancer cells $\left(3 \times 10^{4}\right.$ cells $\left./ \mathrm{mL}\right)$ in DMEM were seeded in 96-well cell culture plates. Cells were treated with AS-605240 $(6 \mu \mathrm{M})$ and/or PTX $(1 \mu \mathrm{M})$. On day 1, 2, 3 and 4, cells were incubated with cck-8 solution (medium: $\operatorname{cck} 8=10: 1$ ) at $37^{\circ} \mathrm{C}$ for $3 \mathrm{~h}$, and absorbance was read at 490 $\mathrm{nm}$ using a microplate reader.

\section{Plate Clone Formation Assay}

MDA-MB-231 cells were dissociated into single cells and seeded in 6-well cell culture plates (500cells/well). Cells were maintained in DMEM containing AS-605240 $(6 \mu \mathrm{M})$ and/or PTX $(1 \mu \mathrm{M})$ for 10-14days. Cells were stained with crystal violet and counted by microscope.

\section{Tumorsphere Assay}

MDA-MB-231 cells were dissociated into single cells and cultured with serum-free DMEM containing $20 \mathrm{ng} / \mathrm{mL}$ EGF, 20ng/mL bFGF. Cells $\left(1 \times 10^{4} /\right.$ well $)$ were seeded in 24-well ultra-low attachment plates (Corning). The number of tumorspheres was counted 14 days after seeding.

\section{Flow Cytometry}

MDA-MB-231 cells were seeded in 6-well cell culture plates and treated with AS-605240 $(6 \mu \mathrm{M})$ and/or PTX $(1 \mu \mathrm{M})$ for 48h. Cells were collected and washed with PBS, and maintained overnight in $70 \%$ ice ethanol at $4^{\circ} \mathrm{C}$. Cells were stained as described in the Annexin V-FITC/PI Apoptosis Detection Kit and measured by flow cytometry.

\section{Hoechst Staining}

MDA-MB-231 cells were seeded in 6-well cell culture plates and treated with AS-605240 $(6 \mu \mathrm{M})$ and/or PTX $(1 \mu \mathrm{M})$ for $48 \mathrm{~h}$. Cells were washed with PBS, and stained as described in the Hoechst 33342 Staining Kit. Representative images were acquired with the fluorescence microscope.

\section{Migration}

Collective cell migration was measured in a woundhealing assay. MDA-MB-231 cells were seeded in 6-well cell culture plates. After cells were full, a portion of the monolayer was scratched with a $100 \mu \mathrm{L}$ pipette tip. At this time, cells were maintained in serum-free DMEM containing AS-605240 $(6 \mu \mathrm{M})$ and/or PTX $(1 \mu \mathrm{M})$, and examined for resealing of the "wounded" monolayer $48 \mathrm{~h}$ later.

\section{Transwell}

MDA-MB-231 cells were seeded in 6-well cell culture plates and treated with AS-605240 $(6 \mu \mathrm{M})$ and/or PTX $(1 \mu \mathrm{M})$ for $48 \mathrm{~h}$. Cells were dissociated into single cells and cultured with serum-free DMEM and seeded 5000 cells/well in upper chamber (transwell insert). In lower chamber added $600 \mu \mathrm{L}$ DMEM with $10 \%$ FBS. After $24 \mathrm{~h}$, cells were stained with crystal violet and counted by microscope.

\section{Mice}

Eight-week-old SCID mice were purchased by Slake Jingda Laboratory Animal Technology Company Hunan province. Mice were injected with $3 \times 10^{6}$ MDA-MB-231 cells into the mammary fat pads. Once tumors formed an area of $30-40 \mathrm{~mm}^{2}$, mice were treated with $18 \mathrm{mg} / \mathrm{kg}$ AS-605240 and $10 \mathrm{mg} / \mathrm{kg}$ PTX, tumors and weight of mice were measured every 3 days for 3 weeks. At the end of the study, mice were euthanized and tumors were obtained for analysis. The research purposes under protocols were approved by the Ethics Committee of the State Key Laboratory of Medical Genetics (NO.2016030901). And the experiment was performed in accordance with the Regulations on the Management of Experimental Animals formulated by the National Science and Technology Commission of China and Measures for the Management of Laboratory Animals in Hunan Province.

\section{qRT-PCR}

RNA was extracted using the TRIzol Up Plus RNA Kit by following the manufacturer's protocol. cDNA was synthesized from $1 \mu \mathrm{g}$ of total RNA using the FastQuant RT Kit as described by the manufacture. qRT-PCR was performed using the SuperReal PreMix Plus and primers are shown in Table 2.

\section{Western Blot}

Cells and tumors were lysed in RIPA buffer, protein concentrations were determined using BCA Protein Assay Kit, and Samples containing an equal amount of total protein were resolved by SDS-PAGE and electrotransferred to PVDF membranes. Membranes were incubated overnight with AKT (Cell Signaling, 4691, 1:2000), p-AKT (Cell Signaling, 4060, 1:2000), Bcl-2 (proteintech, 12789-1-A, 1:1000), Bax (proteintech, 50599-2-lg, 1:1000), Vimentin (Cell Signaling, 5741, 1:1000), E-cadherin (Cell Signaling, 3195, 1:1000), Beclin-1 (Cell Signaling, 3495, 1:1000), 
Table 2 Primers Used for Real-Time PCR

\begin{tabular}{|c|c|}
\hline Genes & Sequence $\left(5^{\prime}-3^{\prime}\right)$ \\
\hline Hu-claudin I & $\begin{array}{l}\text { F: GTGCGATATTTCTTCTTGCAGG } \\
\text { R: TTCGTACCTGGCATTGACTGG }\end{array}$ \\
\hline Hu-claudin3 & $\begin{array}{l}\text { F: CTGCTCTGCTGCTCGTGTCC } \\
\text { R: TTAGACGTAGTCCTTGCGGTCGTAG }\end{array}$ \\
\hline Hu-claudin 4 & $\begin{array}{l}\text { F: GGCTGCTTTGCTGCAACTGTC } \\
\text { R: GAGCCGTGGCACCTTACACG }\end{array}$ \\
\hline Hu-claudin7 & $\begin{array}{l}\text { F: CATCGTGGCAGGTCTTGCC } \\
\text { R: GATGGCAGGGCCAAACTCATAC }\end{array}$ \\
\hline Hu-ALDHI & $\begin{array}{l}\text { F: TGTTAGCTGATGCCGACTTG } \\
\text { R: TTCTTAGCCCGCTCAACACT }\end{array}$ \\
\hline Hu-Vimentin & $\begin{array}{l}\text { F: ATCCAAGTTTGCTGACCTCTCTG } \\
\text { R: TTCCAGGGACTCATTGGTTCC }\end{array}$ \\
\hline Hu-ZEB2 & $\begin{array}{l}\text { F: CGCTTGACATCACTGAAGGA } \\
\text { R: CTTGCCACACTCTGTGCATT }\end{array}$ \\
\hline Hu-EpCAM & $\begin{array}{l}\text { F: CGCAGCTCAGGAAGAATGTG } \\
\text { R: TGAAGTACACTGGCATTGACGA }\end{array}$ \\
\hline Hu-PIK3CG & $\begin{array}{l}\text { F: ATGGAGCTGGAGAACTATAAAC } \\
\text { R: GGCTGAATGTTTCTCTCCT }\end{array}$ \\
\hline Hu-GAPDH & $\begin{array}{l}\text { F: GACCCCTTCATTGACCTCAAC } \\
\text { R: CTTCTCCATGGTGGTGAAGA }\end{array}$ \\
\hline
\end{tabular}

Abbreviations: CLBC, Claudin-low breast cancer; PIK3CG, PI3K catalytic subunit gamma; PTX, paclitaxel; TNBC, Triple negative breast cancer; BLBC, basal-like breast cancer; PR, progesterone receptor; ER $\alpha$, estrogen receptor $\alpha$; HER2, human epidermal growth factor receptor 2; EMT, epithelial-mesenchymal transition; PI3Ks, Phosphatidylinositol 3-kinases; GPCR, G protein coupled receptor.

LC3B (Cell Signaling, 3868, 1:1000), $\beta$-actin (ABclonal, AC004, 1:8000). And then membranes were incubated for $1 \mathrm{~h}$ with HRP-conjugated goat anti-Rabbit antibodies (ABclonal, AS014), HRP-conjugated goat anti-Mouse antibodies (ABclonal, AS003). Immunoreactive products were visualized by chemiluminescence and quantified by densitometry using the ImageJ software.

\section{Statistics}

All data are presented as mean \pm standard error. Statistical Analysis was performed using the two-tailed Student's $t$-test. Criterion for statistical significance was set at $\mathrm{p}<0.05$.

\section{Results}

PIK3CG Was a Potentially Therapeutic

\section{Target for CLBC Patients}

We first established the cell lines from TNBC patients (Figure 1A and B). The CLBC subtype was distinguished from Non-CLBC by the expression levels of CLBC identification markers. We selected 8 genes as CLBC markers, including down-expression of Claudin1, Claudin3, Claudin4, Claudin7, EpCAM and up-expression of ALDH1, Vimentin and ZEB2. If 5 or more out of 8 genes expression levels are in line with expectations, the samples would be considered as CLBC (Figure 1C). It is interesting that PIK3CG expression level was higher in CLBC than in Non-CLBC (Figure 1D). ${ }^{17}$ The higher expression of PIK3CG correlated with worse overall survival rate in breast cancer patients (Figure 1E). The data suggested that PIK3CG was specifically high expressed in CLBC patients' samples and might be potential target for better treatment of CLBC patients.

\section{Targeting PIK3CG Potentiated CLBC Cells Growth Inhibition in 2D and 3D Cultures by PTX}

According to the data using Non-CLBC, CLBC and ER+ subtype primary cells treated with AS-605240 $(6 \mu \mathrm{M})$ and/or PTX $(1 \mu \mathrm{M})$, we found that CLBC cells were more sensitive to treatment by drug combination of the AS-605240 $(6 \mu \mathrm{M})$ and PTX $(1 \mu \mathrm{M})$ (Figure 2A and B). MDA-MB-231 and MCF-7 cell lines were CLBC and ER+ subtype breast cancer cells respectively. ${ }^{19}$ From the CCK8 experiments results, rate of cell viability using MDA-MB-231 was lower than MCF-7, which was consistent with the data by using primary culture breast cancer cells (Figure 2C and D). Colony-forming assay and tumor spheres experiment were pursued to further confirm that inhibition of PIK3CG activation could potentiate CLBC cells growth inhibition by PTX in $2 \mathrm{D}$ and $3 \mathrm{D}$ cultures (Figure 2E, F and G). AKT was the critical proteins on down-stream of PIK3CG signal pathway. ${ }^{20}$ We found that PTX treatment could significantly enforce the PIK3CG function for p-AKT protein levels dramatically decreased by concomitant drugs (Figure 2H).

\section{The Apoptotic Rate of CLBC Cells Induced by PTX Was Enforced by Inhibiting the PIK3CG Activation}

Activating apoptosis pathway with chemical drugs was a clinically validated approach to cancer therapy. ${ }^{21}$ Our data by flow cytometry showed that the late stage apoptotic rate increased in MDA-MB-231 cells treated with AS605240 and/or PTX (Figure 3A). The late apoptotic rate was the highest when using the combined treatment (Figure 3B). In the meantime, more than $40 \%$ of total MDA-MB-231 cells in apoptotic stage when treated by 
A

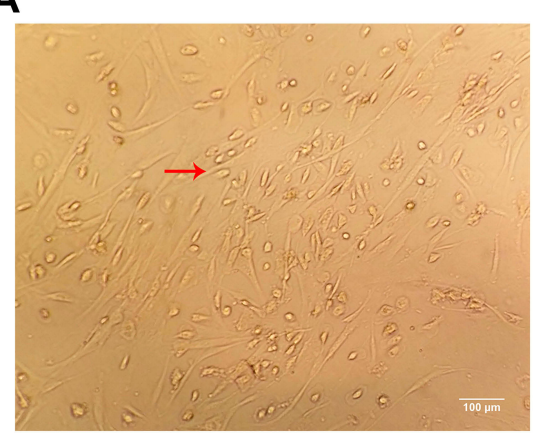

B

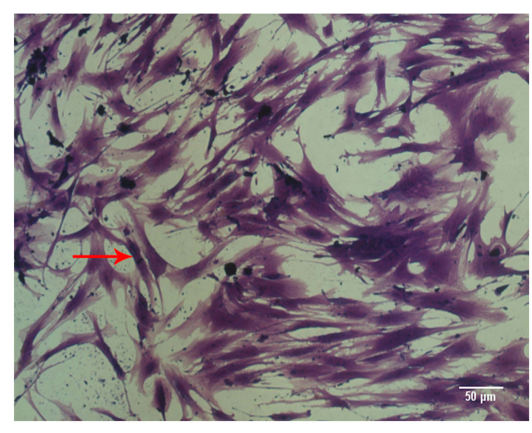

C

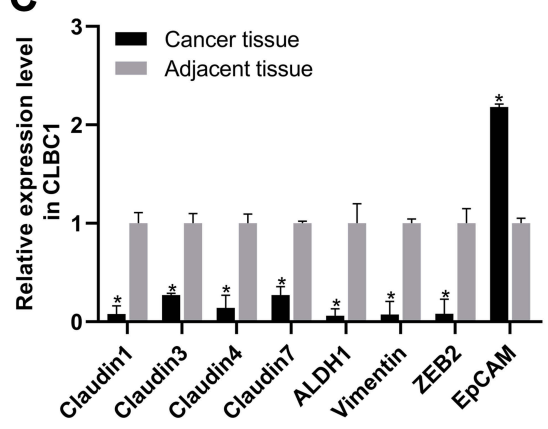

D

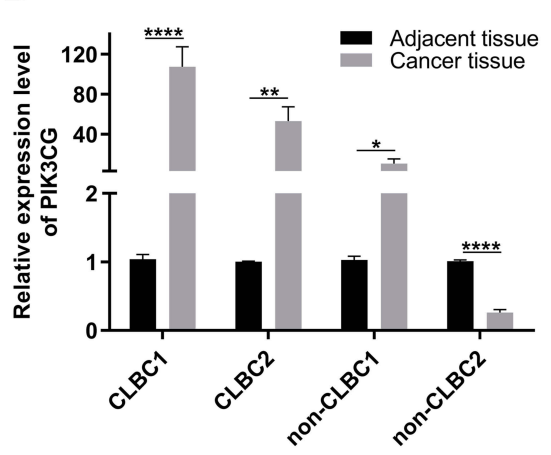

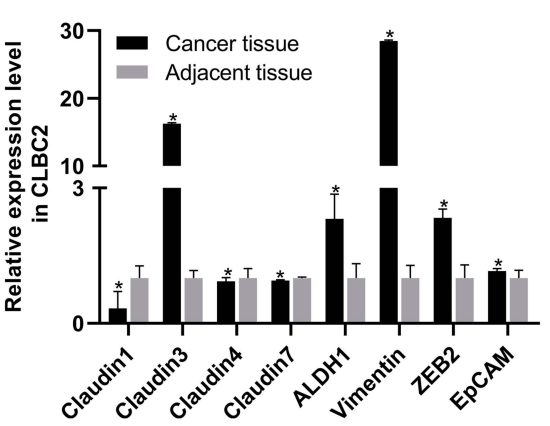

$\mathbf{E}$

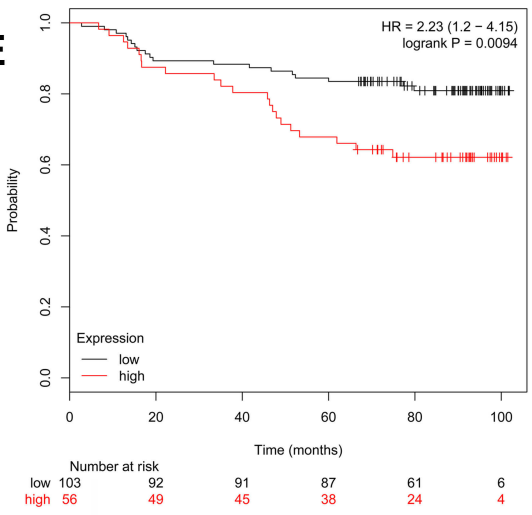

Figure I PIK3CG was a potentially therapeutic target. (A) Images of CLBC patients' cells in 2D culture. Red arrow indicates single CLBC cell. (B) CLBC patients' cells were stained with crystal violet. Red arrow indicates single CLBC cell. (C) Relative expression of Claudin I, Claudin3, Claudin4, Claudin7, EpCAM, ALDHI, Vimentin and ZEB in CLBCI and CLBC2 by qPCR. (D) Relative expression of PIK3CG in CLBCI, CLBC2, Non-CLBCI and Non-CLBC2 by qPCR. (E) The correlation of PIK3CG expression level and survival rate of patients with breast cancer by the analysis of GSEI456. $* \mathrm{P}<0.05, * * \mathrm{P}<0.005$, $* * * * \mathrm{P}<0.0000$ I.

AS-605240 and PTX together suggested that concomitant drugs was an effectively therapeutic methods (Figure 3C and D). The expression level of Bcl-2 and Bax protein was related with apoptosis and could predict clinical outcome. $^{22}$ The ratio of $\mathrm{Bax} / \mathrm{Bcl}-2$ was the lowest in MDA-MB-231 cells treated with concomitant drugs among all groups (Figure $3 \mathrm{E}$ and F). All the above data showed that apoptosis of CLBC cells was further activated with the strategy of combination therapy.

\section{Targeting PIK3CG in Combination with PTX Significantly Suppressed Migration of CLBC Cells}

Metastasis and invasion are always occurring in patients with advanced breast cancer, and are related with poor prognosis. $^{23}$ The results from our wound-healing assay and transwell suggested that migration of MDA-MB-231 cells could be significantly suppressed by PTX in combination with AS-605240 (Figure 4A-D). Vimentin and E-cadherin were regarded as major proteins related with epithelial-mesenchymal transition and clinical outcome. ${ }^{24}$
Western blot assay showed that concomitant drugs treatment for MDA-MB-231 cells could significantly downregulate Vimentin expression and up-regulate E-cadherin expression (Figure 4E and F), which suggested that it is more effective for the treatment of CLBC when using concomitant drugs than single drug.

\section{Manipulating Autophagy Was a Validated Approach for the Use of PIK3CG Inhibitor}

Manipulating autophagy was a validated approach for the use of PIK3CG inhibitor. Autophagy manipulation could be a strategy to improve antitumor therapies. ${ }^{25}$ Autophagy activation may help cancer cells to adapt to cellular stress, which also happened from our experiments. Western blot assay of Beclin-1 and LC3B showed that autophagy level increased when MDA-MB-231 cells were treated by single drug of AS-605240 $(6 \mu \mathrm{M})$ or PTX $(1 \mu \mathrm{M})$, but it is very interesting that inhibition of autophagy occurred when the CLBC cells were treated with AS-605240 $(6 \mu \mathrm{M})$ and PTX $(1 \mu \mathrm{M})$ compared with group of single drug treatment for 
A
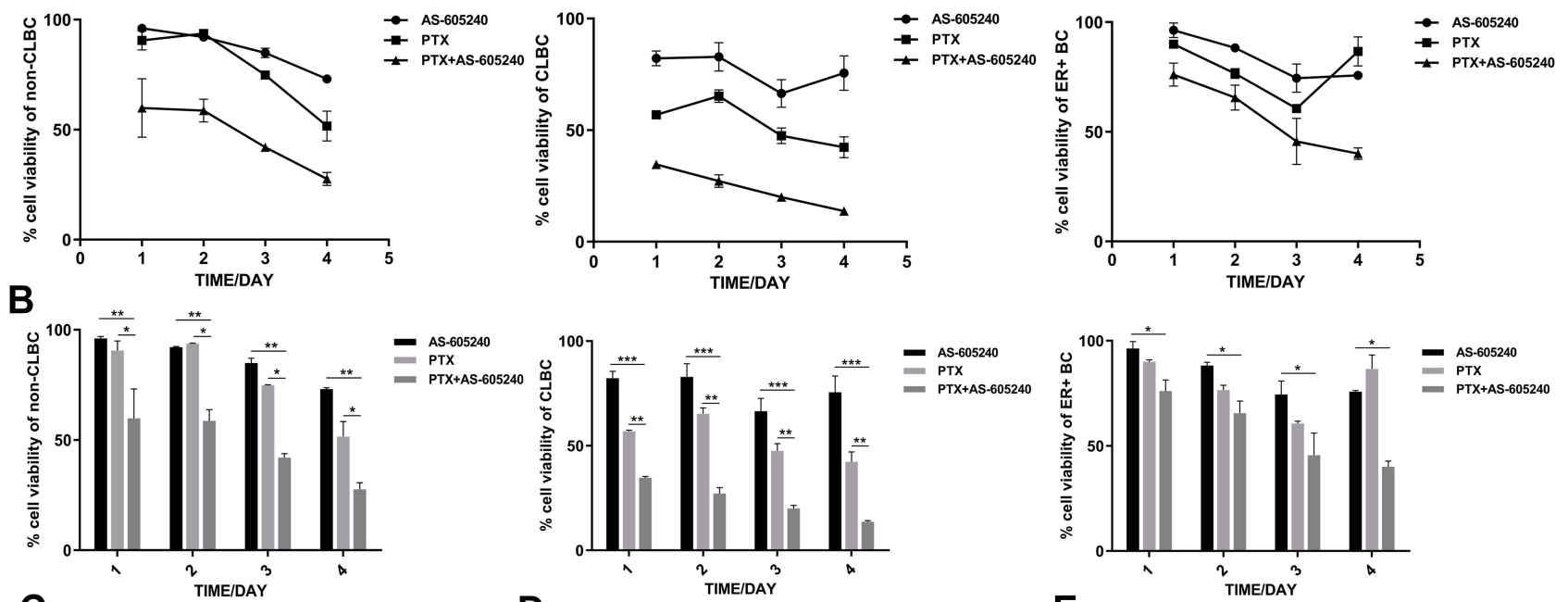

C

D

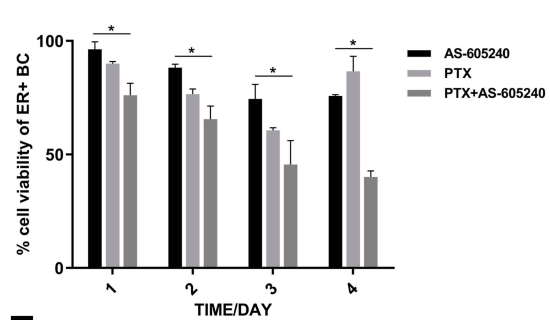

E
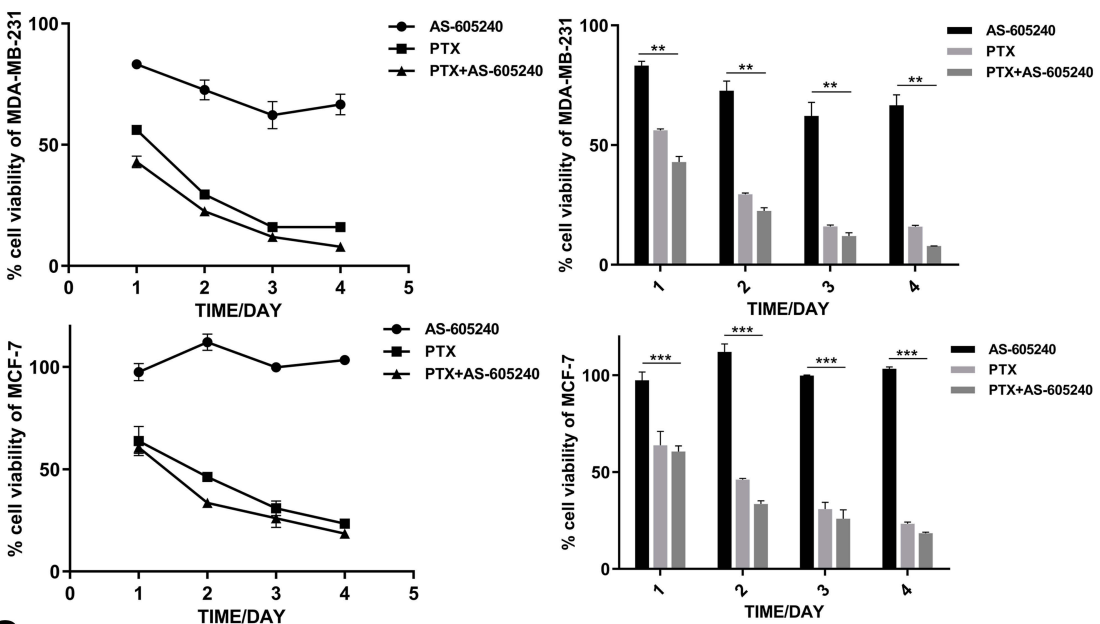

PTX
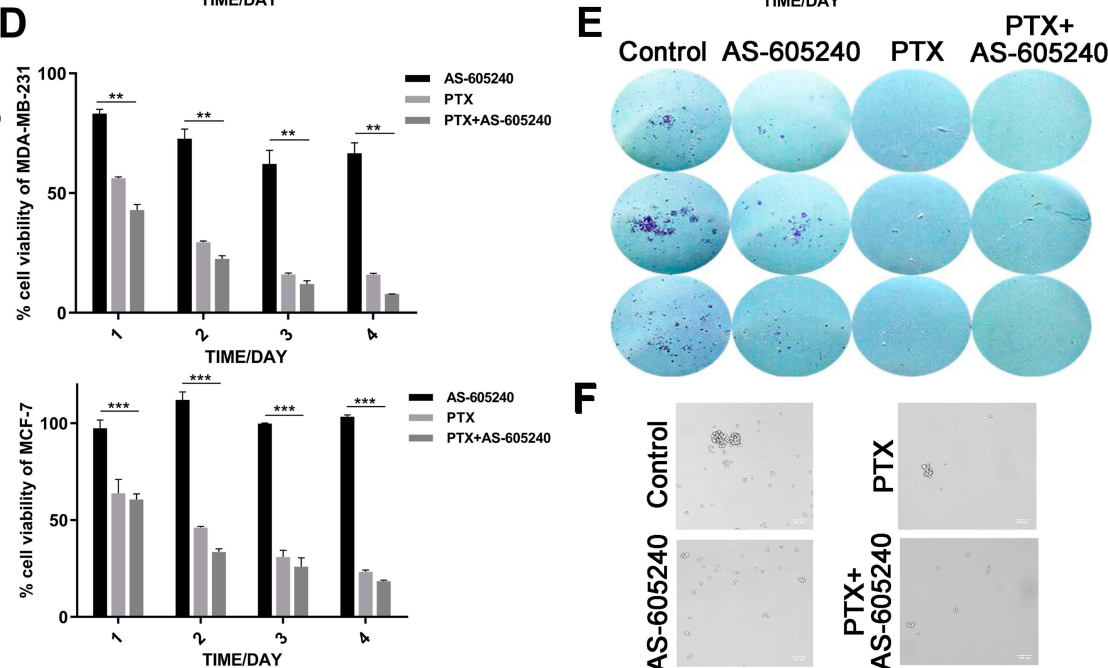

G
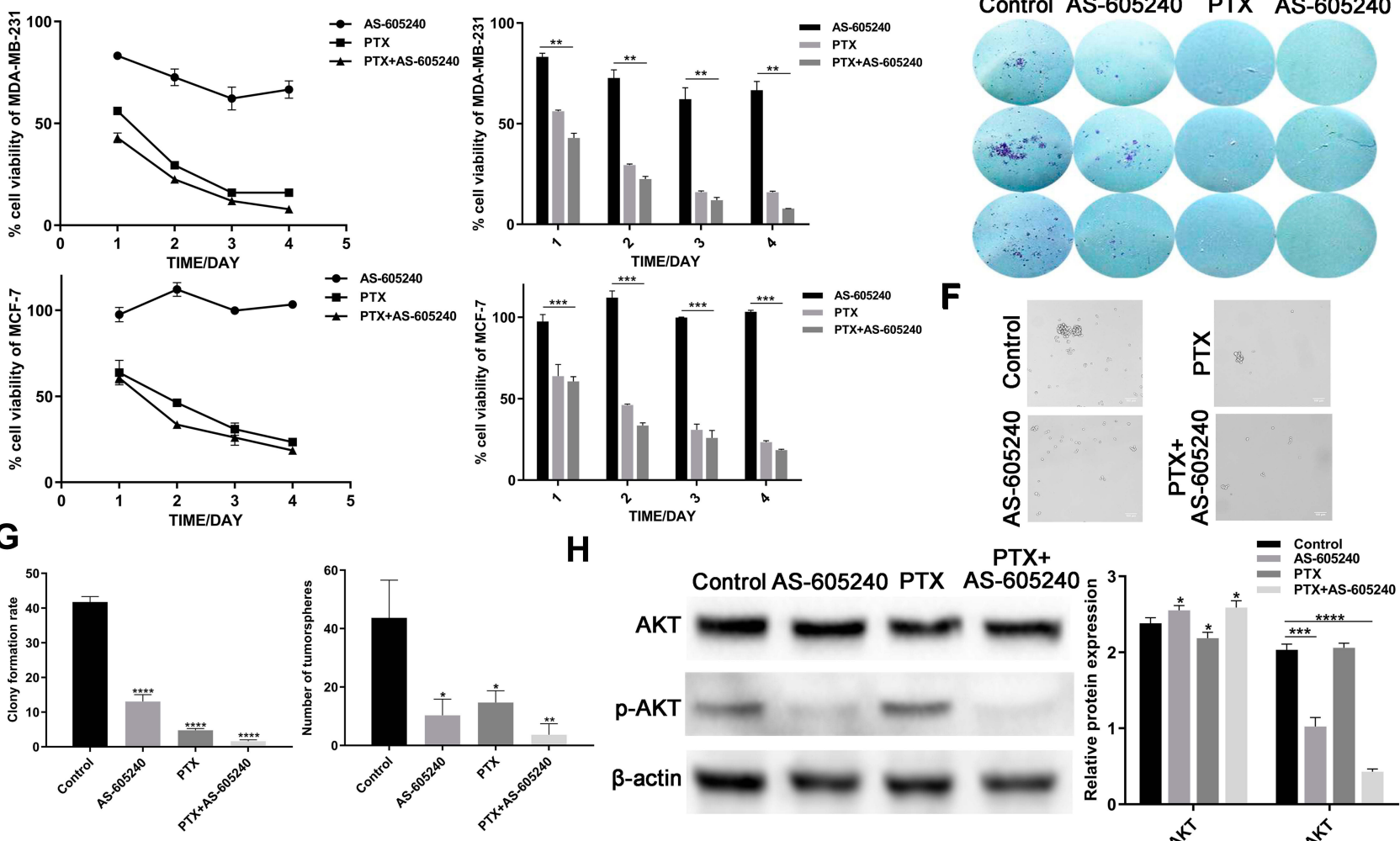

$\mathbf{F}$
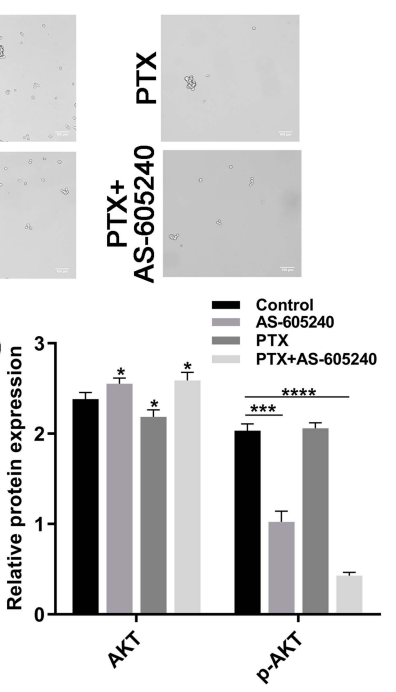

Figure 2 The growth of CLBC cells were treated with drugs in 2D and 3D cultures. (A) Growth curve of Non-CLBC, CLBC and ER+ cells treated with AS-605240 (6 $\mu M$ ) and/or PTX $(I \mu \mathrm{M})$ for $24,48,72$ and 96 hours by CCK8 experiments. (B) Cell viability rate of the 3 above primary culture cells was calculated depending on growth curve.

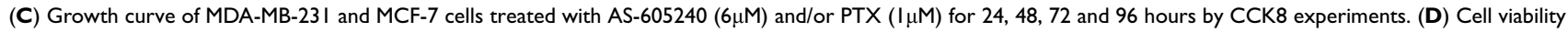
rate of the MDA-MB-23I and MCF-7 cells was calculated depending on growth curve. (E) Colony-forming assay for MDA-MB-23I cells after I4 days of continuous treatment with AS-605240 $(6 \mu \mathrm{M})$ and/or PTX $(1 \mu \mathrm{M})$. DMSO treatment was used as the control group. (F) Representative photomicrographs of tumorspheres formed by MDA-MB -23 I cells with continuous treatment with AS-605240 $(6 \mu \mathrm{M})$ and/or PTX $(1 \mu \mathrm{M})$ for 2 weeks in 3D cultures. DMSO treatment was used as the control group. (G) The rate of clone formed per 500 cells and quantification of tumorspheres formed per 20,000 cells depending on $E$ and $F$. (H) Analysis of total AKT and p-AKT protein levels by Western blot using MDA-MB-23I cells treatment with AS-605240 $(6 \mu \mathrm{M})$ and/or PTX $(1 \mu \mathrm{M})$. DMSO treatment was used as the control group. Bars represent the mean \pm S.E. of protein levels, normalized by $\beta$-actin expression levels. * $\mathrm{P}<0.05$, $* * \mathrm{P}<0.005$, $* * * \mathrm{P}<0.0005$, $* * * * \mathrm{P}<0.0000 \mathrm{I}$.

48 hours (Figure 5A). Then, we found that Beclin-1 level increased when the CLBC cells were treated with AS$605240(6 \mu \mathrm{M})$ and PTX $(1 \mu \mathrm{M})$ for $8,16,32$ hours, while it decreased at 48 hours (Figure 5B). These results suggested that inhibition of PIK3CG might improve the therapeutic effect of PTX by reversing autophagy 

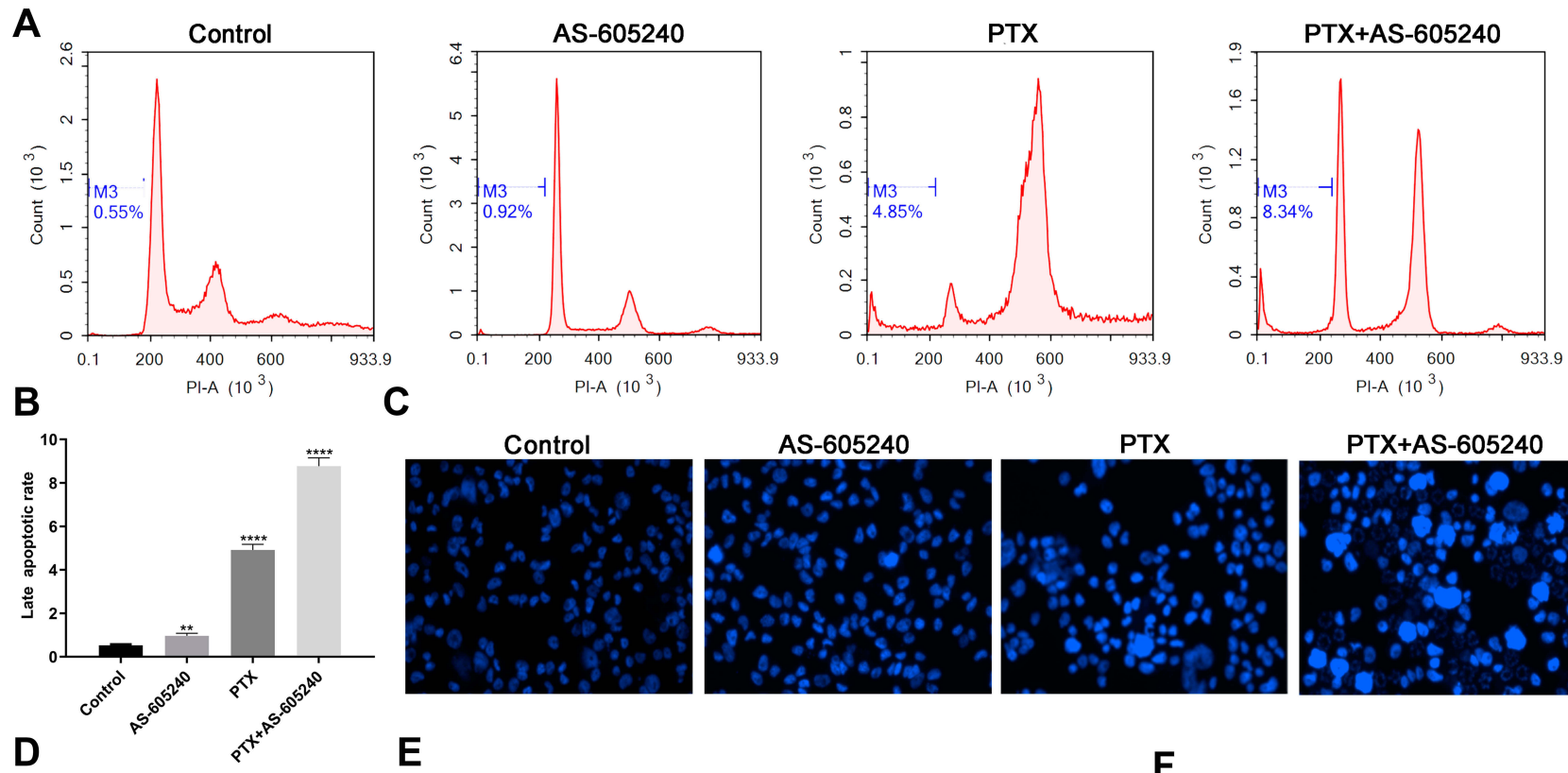
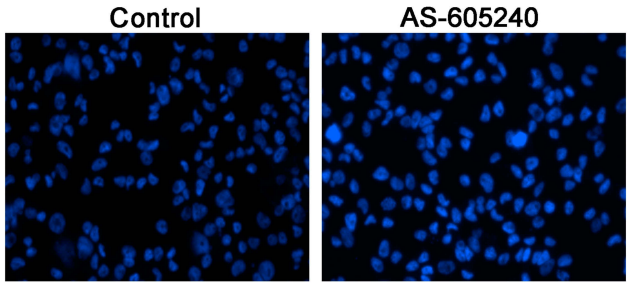

$\mathbf{E}$

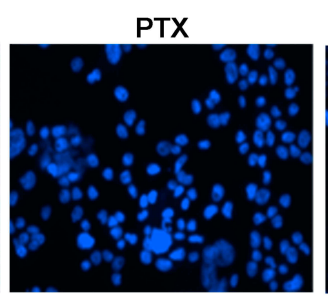

PTX+AS-605240
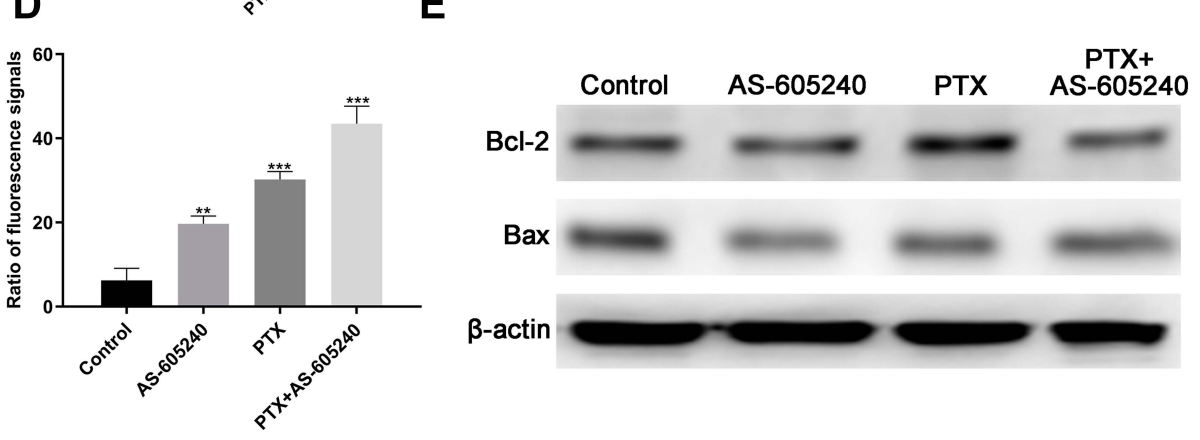

$\mathbf{F}$

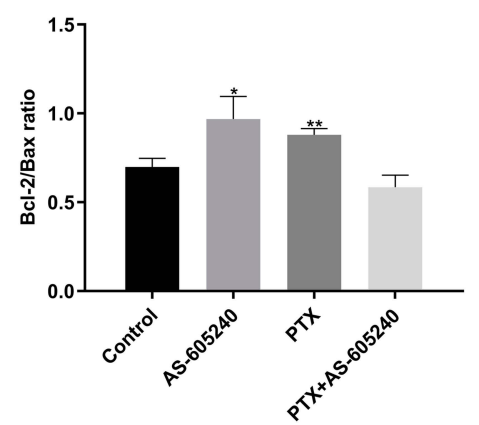

Figure 3 The apoptotic rate of CLBC cells were treated with drugs. (A) MDA-MB-23I cells treated with AS-605240 (6 $\mu$ M) and/or PTX (I $\mu$ M) and late stage apoptosis was checked by flow cytometry. DMSO treatment was used as the control group. (B) The late apoptotic rate was statistically analyzed depending on A. (C) MDA-MB-23I cells treated with AS-605240 $(6 \mu \mathrm{M})$ and/or PTX $(I \mu \mathrm{M})$ and then stained by Hoechst 33342 (D) Column diagram indicating the ratio fluorescence signals per high power microscope field and the statistical analysis results depending on C. (E) Western blot analysis of Bcl-2 and Bax using MDA-MB-23I cells treatment with AS-605240 (6 $\mu$ M) and/or PTX $(I \mu M)$. DMSO treatment was used as the control group. (F) Analysis of Bax/Bcl-2 ratio by the Image software depending on $\mathbf{E}$. Bars represent the mean $\pm \mathrm{S}$. E. of $\mathrm{Bax} / \mathrm{Bcl}-2$ ratio. $* \mathrm{P}<0.05$, $* * \mathrm{P}<0.005$, $* * * \mathrm{P}<0.0005$, ****P $<0.0000 \mathrm{I}$.

activation. Moreover, inhibition of autophagy by $\mathrm{CQ}$ might reinforce the cell growth suppressed by AS605240 (Figure 5C and D).

\section{In vivo Combination Treatment by AS-605240 and PTX Providing Promising Therapeutic Regimen for CLBC Tumors}

Our data in vivo showed that combined drugs of AS605240 and PTX could significantly inhibit tumor size after the mice models were treated for 15 days, while had no effect on the weight of mice (Figure 6A and B). These above results clearly indicated that CLBC tumors in vivo could be well treated with a strategy of combined drugs.

\section{Discussion}

CLBC subtype designation is based on a transcriptional signature indicating lack of claudins protein expression that are components of tight junctions. CLBC is an aggressive subtype of TNBC that confers poor prognosis and specific therapeutic vulnerability, unlike HER2 or ER-expressing positive subtypes or BRCA mutant TNBC. ${ }^{5}$ Our previous results show that PIK3CG, related with life span and prognosis, may be a potential target for the treatment of CLBC. However, the inhibition of PIK3CG activation by AS-605240 individually in CLBC cells can only inhibit cell migration and stemness, but not cell growth. The cancer cells will not succumb to apoptosis by inhibition of PIK3CG alone. Thus, it is important 
A
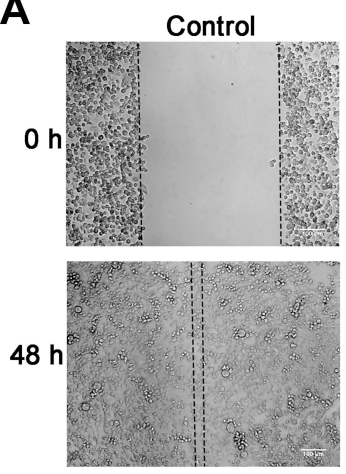

C

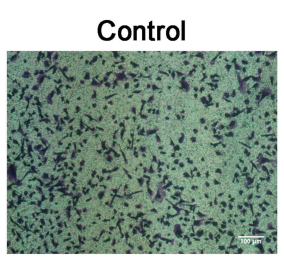

$\mathbf{E}$

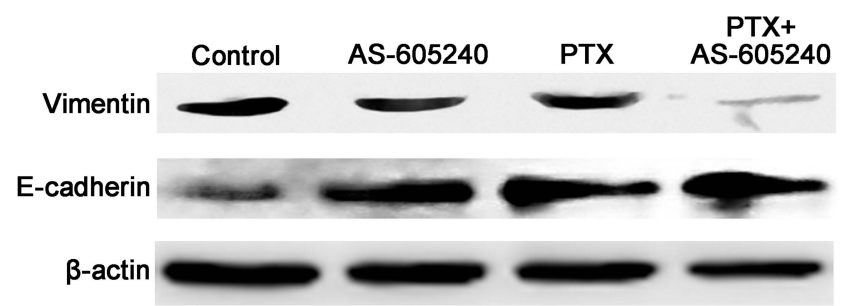

PTX
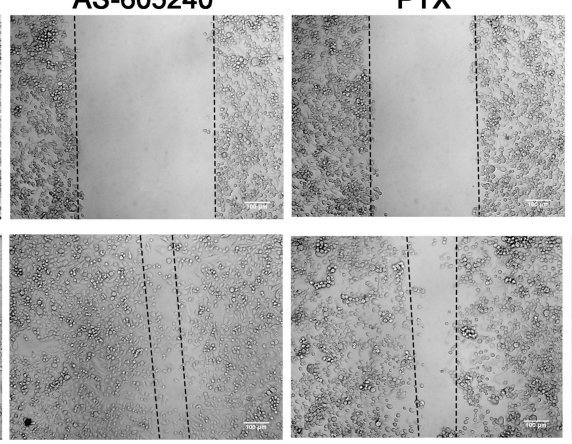

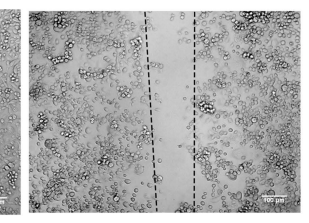

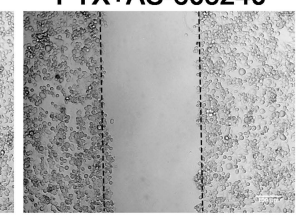

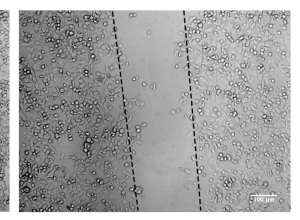

\section{D}

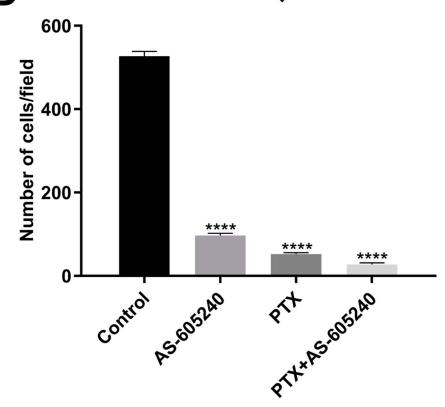

$\mathbf{F}$

B
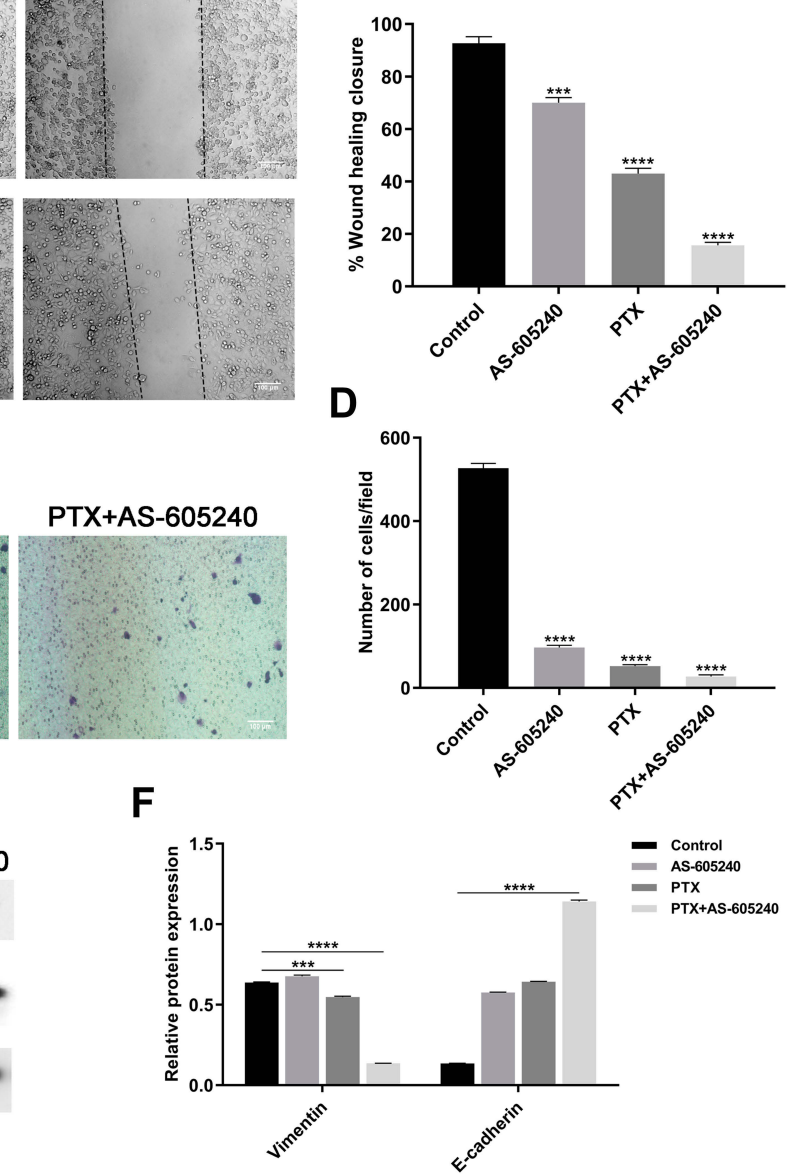

Figure 4 The migration of CLBC cells were treated with drugs. (A) Representative images of wound-healing assay. MDA-MB-23I cells were incubated with AS-605240 $(6 \mu \mathrm{M})$ and/or PTX $(\mathrm{I} \mu \mathrm{M})$ or DMSO as control. (B) Statistical analysis of wound-healing closure depending on A. (C) Representative images of transwell assay. MDA-MB-23I cells were treated with AS-605240 $(6 \mu \mathrm{M})$ and/or PTX $(\mathrm{I} \mu \mathrm{M})$ or DMSO as control. (D) Statistical analysis of invading cell counts per high power microscope field. (E)

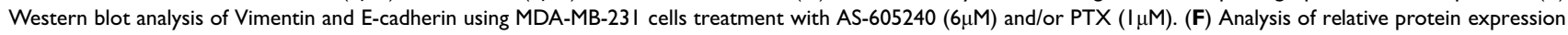
depending on $\mathbf{E}$. Bars represent the mean \pm S.E. of protein levels, normalized by $\beta$-actin expression levels. $* * * P<0.0005$, *****P<0.0000 I.

to find a better way to improve therapeutic efficacy of targeted PIK3CG.

PTX is a classical drug for the treatment of TNBC, while drug resistant and relapse are the major obstacles to the better prognosis. ${ }^{26}$ For severe side effects occurring in patients with high dose of PTX, it is critical to reduce the dose while maintaining its cancer fighting effect. ${ }^{27}$ In our study, the combination of PIK3CG inhibitor (AS-605240) and PTX may provide new effectively therapeutic method of CLBC. On one side, PTX can help AS-605240 to kill the cancer cells. On the other side, the inhibition of PIK3CG activation may decrease the dose of PTX and increase cancer cells' susceptibility. Our results suggested that target PIK3CG potentiates the 2D and 3D grow inhibition by PTX. Moreover, the population of cancer stem cells deceases and the migration rate is significantly suppressed. Both stemness and metastasis are the main characteristics of malignant cancer. The effects of combination AS-605240 and PTX further confirm that the targeting PIK3CG is a reasonable method to cure the CLBC.

Many mechanisms are involved in the effective treatment of breast cancer. As a traditional chemotherapy drug, PTX can induce the apoptosis and stop cell cycle at a specific check point. Our results show that the susceptibility of cancer cells to apoptosis by the combination of PTX and AS-605240 is more significant in MDA-MB-231 than MCF-7, which is consistent with our data that PIK3CG may be a specific target in CLBC. ${ }^{17}$ The ratio of $\mathrm{Bcl}-2 / \mathrm{Bax}$ is considered to be more critical than the expression level of individual proteins in determining the susceptibility of cancer cells to apoptosis. $^{28}$ In our study, the value of $\mathrm{Bcl}-2 / \mathrm{Bax}$ 


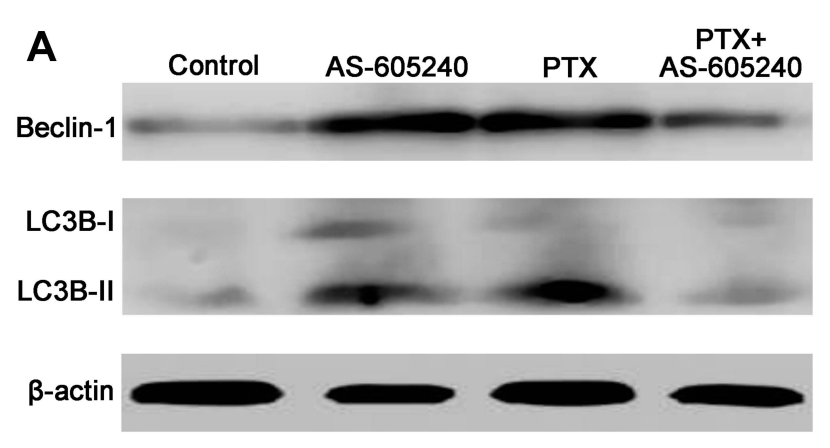

B
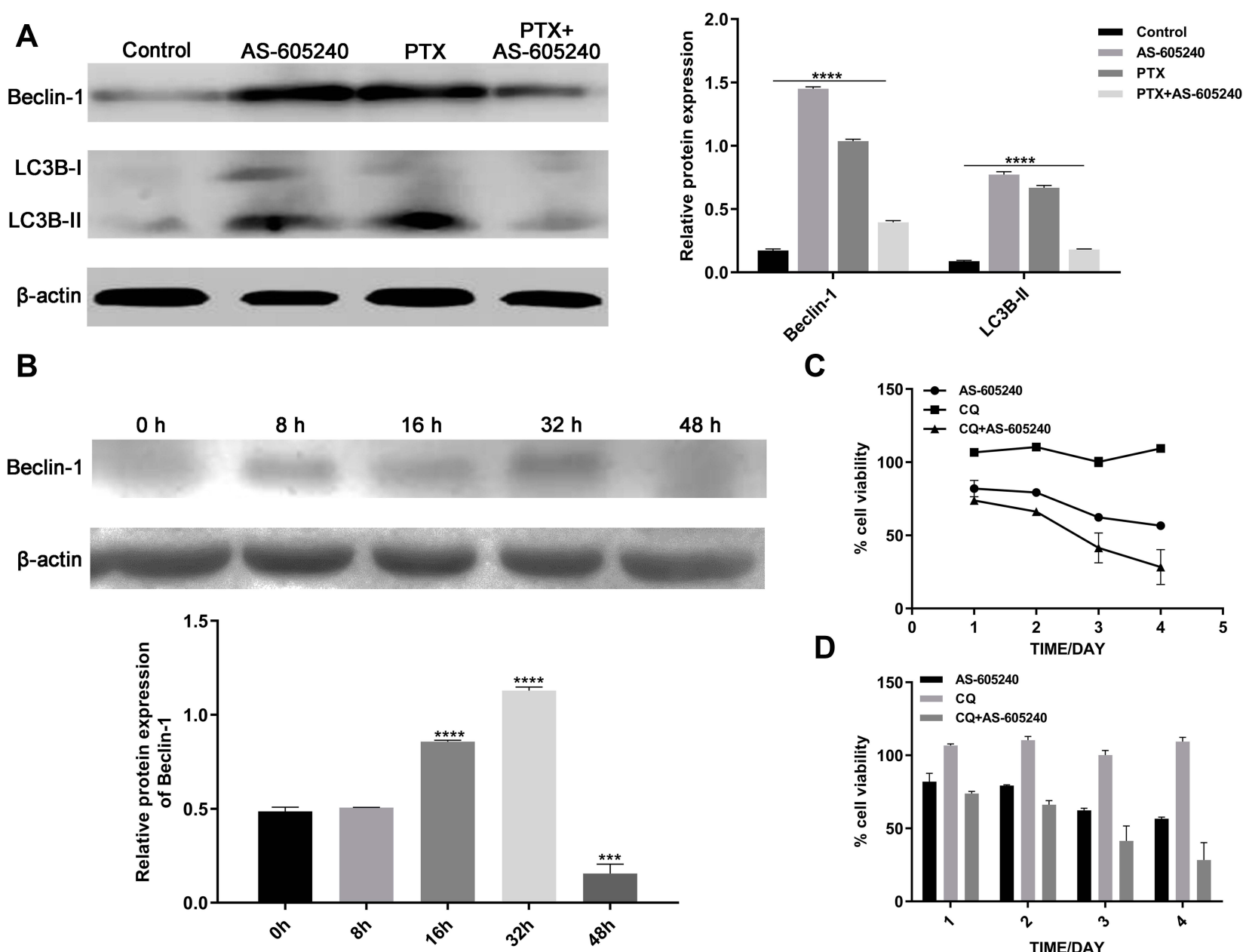

D
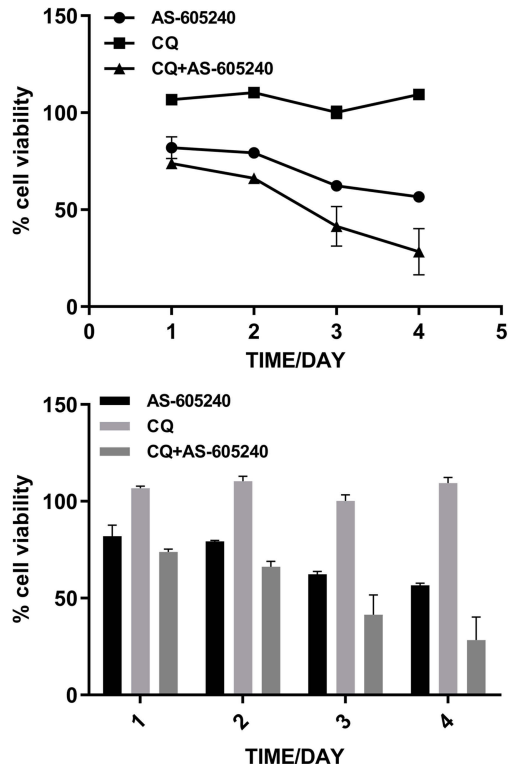

Figure 5 The Autophagy of CLBC cells were treated with drugs. (A) Analysis of Beclin-I and LC3B protein levels by Western blot using MDA-MB-23I cells treatment with AS$605240(6 \mu \mathrm{M})$ and/or PTX $(\mathrm{I} \mu \mathrm{M})$ or DMSO as control for 48 hours. Bars represent the mean \pm S.E. of protein levels, normalized by $\beta$-actin expression levels. (B) Analysis of Beclin-

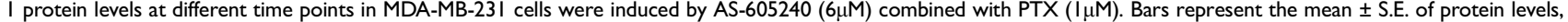
normalized by $\beta$-actin expression levels. (C) Growth curve was determined by cck-8 when MDA-MB-23I cells were treated with AS-605240 (6 $\mu M)$ and/or chloroquine (I $\mu$ M) for $24,48,72$ and 96 hours. (D) Column graph for the rate of cell viability was described depending on growth curve. $* * * \mathrm{P}<0.0005$, $* * * * \mathrm{P}<0.0000 \mathrm{I}$.

A

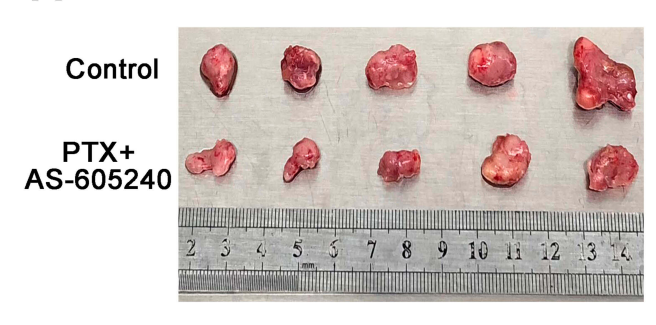

B

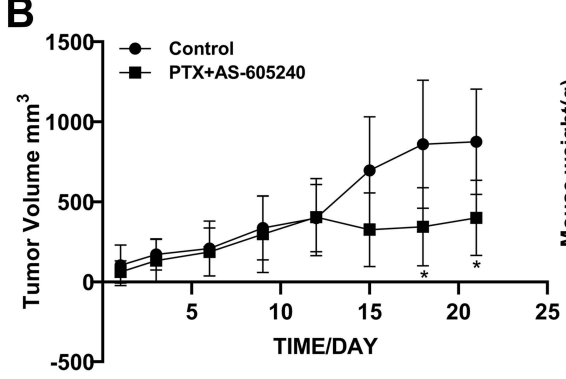

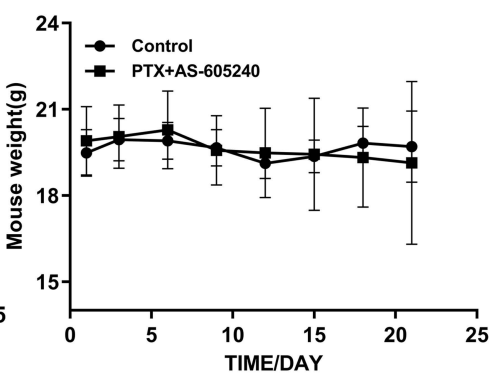

Figure 6 The mice weight and CLBC tumors size. (A) MDA-MB-23I cells were employed to establish a CLBC xenograft model treated with concomitant drugs of AS$605240(18 \mathrm{mg} / \mathrm{kg})$ and PTX $(10 \mathrm{mg} / \mathrm{kg})$ for 3 weeks. Then, mice were euthanized and tumors were obtained. (B) Tumors size and mice weight were measured every 3 days for 3 weeks. $* \mathrm{P}<0.05$.

decreases dramatically in MDA-MB-231 cells treated with both PTX and AS-605240 at the same time. Inhibition of cancer invasion and metastasis is another important method for better treatment of malignant tumors. $^{29}$ From the data by wound healing and transwell experiments, we found the migration of MDA-MB-231 cells was significantly inhibited with combined treatment. Dramatically decreased level of vimentin and increased 
level of E-cadherin was detected by Western blot experiments. These data further confirm that AS-605240 can reinforce the therapeutic effect of PTX on CLBC.

Autophagy is a kind of mechanism usually happened when cancer cells are in a drug treatment environment, promotes tumor initiation and progression by maintaining cellular homeostasis and cell viability. ${ }^{30}$ Beclin-1 and LC3 are two critical factors involved in the process of autophagy and cancer chemotherapy. ${ }^{31}$ Autophagy activation can contribute PTX resistance development through inhibiting apoptosis in breast cancer. ${ }^{32}$ Our results showed that autophagy was prevented when using the combined AS605240 and PTX compared to individual drug in MDAMB-231 cells. Autophagy inhibition with chemotherapy may be an effective strategy to overcome the PTXresistance in TNBC patients. ${ }^{33}$ Therefore, the combination therapy by AS-605240 and PTX may be a kind of strategy for better treatment of breast cancer. In the meantime, it is of great value to find that the growth inhibition of MDAMB-231 by AS-605240 was enforced by autophagy inhibition with $C Q$, the mechanism involved in which need to be further clarified.

Finally, the data using xenograft-SCID mice as human CLBC model show that the tumor volumes in AS-605240 and PTX combination group were significantly inhibited compared the control group. The results in vivo suggested that concomitant drugs of AS-605240 and PTX maybe provide a good method to treat the CLBC disease.

\section{Conclusion}

In conclusion, the data presented in this paper show that the combined treatment with PTX and AS-605240 may improve the outcome of CLBC by standard chemotherapy, especially for the patients who cannot tolerate the full dose of PTX. Importantly, these results support that PIK3CG is a potential target for better treatment of CLCB.

\section{Acknowledgments}

This research was funded by the National Natural Science Foundation of China, grant number 81672632 and 81972312, Science and Technology Major Projects of Hunan Province, Grant number No. 2018SK1020, Research Innovation Program for graduates of Central South University, Grant number 2018zzts389 and National Undergraduate Training Program for Innovation and Entrepreneurship of Central South University, Grant number 201810533403.

\section{Disclosure}

The authors report no conflicts of interest in this work.

\section{References}

1. Zhang S, Chung W-C, Miele L, et al. Targeting Met and Notch in the Lfng-deficient, Met-amplified triple-negative breast cancer. Cancer Biol Ther. 2014;15(5):633-642. doi:10.4161/cbt.28180

2. Cretella D, Fumarola C, Bonelli M, et al. Pre-treatment with the CDK4/6 inhibitor palbociclib improves the efficacy of paclitaxel in TNBC cells. Sci Rep. 2019;9(1):13014. doi:10.1038/s41598-019-49484-4

3. Goto Y, Thike AA, Ong CCH, et al. Characteristics, behaviour and role of biomarkers in metastatic triple-negative breast cancer. $J$ Clin Pathol. 2019.

4. Prat A, Karginova O, Parker JS, et al. Characterization of cell lines derived from breast cancers and normal mammary tissues for the study of the intrinsic molecular subtypes. Breast Cancer Res Treat. 2013;142(2):237-255. doi:10.1007/s10549-013-2743-3

5. Matsunuma R, Chan DW, Kim B-J, et al. DPYSL3 modulates mitosis, migration, and epithelial-to-mesenchymal transition in claudin-low breast cancer. Proc Natl Acad Sci U S A. 2018;115(51):E11978E11987. doi:10.1073/pnas.1810598115

6. Taylor NA, Vick SC, Iglesia MD, et al. Treg depletion potentiates checkpoint inhibition in claudin-low breast cancer. J Clin Invest. 2017;127(9):3472-3483. doi:10.1172/JCI90499

7. Knezevic J, Pfefferle AD, Petrovic I, et al. Expression of miR-200c in claudin-low breast cancer alters stem cell functionality, enhances chemosensitivity and reduces metastatic potential. Oncogene. 2015;34(49):5997-6006. doi:10.1038/onc.2015.48

8. Usary J, Zhao W, Darr D, et al. Predicting drug responsiveness in human cancers using genetically engineered mice. Clin Cancer Res. 2013;19(17):4889-4899. doi:10.1158/1078-0432.CCR-13-0522

9. Reeder A, Attar M, Nazario L, et al. Stress hormones reduce the efficacy of paclitaxel in triple negative breast cancer through induction of DNA damage. Br J Cancer. 2015;112(9):1461-1470. doi:10.1038/bjc.2015.133

10. Kumari S, Mohan MG, Shailender G, et al. Synergistic enhancement of apoptosis by coralyne and paclitaxel in combination on MDA-MB231 a triple-negative breast cancer cell line. J Cell Biochem. 2019;120(10):18104-18116. doi:10.1002/jcb.29114

11. Han J, Han B, Wu X, et al. Knockdown of lncRNA H19 restores chemo-sensitivity in paclitaxel-resistant triple-negative breast cancer through triggering apoptosis and regulating Akt signaling pathway. Toxicol Appl Pharmacol. 2018;359:55-61. doi:10.1016/j.taap. 2018.09.018

12. Malek M, Kielkowska A, Chessa T, et al. PTEN regulates PI(3,4)P2 signaling downstream of class I PI3K. Mol Cell. 2017;68(3):566-580 e10. doi:10.1016/j.molcel.2017.09.024

13. Hawkins PT, Stephens LR. PI3Kgamma is a key regulator of inflammatory responses and cardiovascular homeostasis. Science. 2007;318 (5847):64-66. doi:10.1126/science.1145420

14. Kaneda MM, Messer KS, Ralainirina N, et al. PI3Kgamma is a molecular switch that controls immune suppression. Nature. 2016;539(7629):437-442. doi:10.1038/nature19834

15. Subramaniam PS, Whye D, Efimenko E, et al. Targeting nonclassical oncogenes for therapy in T-ALL. Cancer Cell. 2012;21(4):459-472. doi:10.1016/j.ccr.2012.02.029

16. Martin D, Galisteo R, Molinolo AA, et al. PI3Kgamma mediates kaposi's sarcoma-associated herpesvirus vGPCR-induced sarcomagenesis. Cancer Cell. 2011;19(6):805-813. doi:10.1016/j.ccr.2011. 05.005

17. Zhang S, Chung W-C, Wu G, et al. Manic fringe promotes a claudin-low breast cancer phenotype through notch-mediated PIK3CG induction. Cancer Res. 2015;75(10):1936-1943. doi:10.1158/0008-5472.CAN14-3303 
18. Xie Y, Abel PW, Kirui JK, et al. Identification of upregulated phosphoinositide 3-kinase gamma as a target to suppress breast cancer cell migration and invasion. Biochem Pharmacol. 2013;85(10):1454-1462. doi:10.1016/j.bcp.2013.03.001

19. Lehmann BD, Bauer JA, Chen X, et al. Identification of human triple-negative breast cancer subtypes and preclinical models for selection of targeted therapies. J Clin Invest. 2011;121(7):2750-2767. doi:10.1172/JCI45014

20. Li M, Sala V, De Santis MC, et al. Phosphoinositide 3-kinase gamma inhibition protects from anthracycline cardiotoxicity and reduces tumor growth. Circulation. 2018;138(7):696-711. doi:10.1161/ CIRCULATIONAHA.117.030352

21. van Delft MF, Chappaz S, Khakham Y, et al. A small molecule interacts with VDAC2 to block mouse BAK-driven apoptosis. Nat Chem Biol. 2019;15(11):1057-1066. doi:10.1038/s41589-019-0365-8

22. Yayu H, Changmao Z, Yijun Dai et al. Recurrent and metastatic extragastrointestinal stromal tumors of the mesentery with C-KIT and PDGFRA mutations: a case report. Cancer Biol Ther. 2019;1-7.

23. Sato J, Shimomura A, Kawauchi J, et al. Brain metastasis-related microRNAs in patients with advanced breast cancer. PLoS One. 2019;14(10):e0221538. doi:10.1371/journal.pone.0221538

24. Yamashita N, Tokunaga E, Iimori M, et al. Epithelial paradox: clinical significance of coexpression of E-cadherin and vimentin with regard to invasion and metastasis of breast cancer. Clin Breast Cancer. 2018;18(5):e1003-e1009. doi:10.1016/j.clbc.2018. 02.002

25. Cirone M, Gilardini Montani MS, Granato M, et al. Autophagy manipulation as a strategy for efficient anticancer therapies: possible consequences. J Exp Clin Cancer Res. 2019;38(1):262. doi:10.1186/ s13046-019-1275-z
26. Liu T, Sun H, Zhu D, et al. TRA2A promoted paclitaxel resistance and tumor progression in triple-negative breast cancers via regulating alternative splicing. Mol Cancer Ther. 2017;16(7):1377-1388. doi:10.1158/1535-7163.MCT-17-0026

27. Shetti D, Zhang B, Fan C, et al. Low dose of paclitaxel combined with XAV939 attenuates metastasis, angiogenesis and growth in breast cancer by suppressing Wnt signaling. Cells. 2019;8(8):892. doi: $10.3390 /$ cells 8080892

28. Saxena A, Viswanathan S, Moshynska O, et al. Mcl-1 and Bcl-2/Bax ratio are associated with treatment response but not with Rai stage in B-cell chronic lymphocytic leukemia. Am J Hematol. 2004;75 (1):22-33. doi:10.1002/ajh.10453

29. Su S-C, Hsieh M-J, Yang W-E, et al. Cancer metastasis: mechanisms of inhibition by melatonin. J Pineal Res. 2017;62(1):e12370. doi:10.1111/jpi.12370

30. Gao L, Dou Z-C, Ren W-H, et al. CircCDR1as upregulates autophagy under hypoxia to promote tumor cell survival via AKT/ERK(1/ 2)/mTOR signaling pathways in oral squamous cell carcinomas. Cell Death Dis. 2019;10(10):745. doi:10.1038/s41419-019-1971-9

31. Yang M, YANG XM, YIN DH, et al. Beclin1 enhances cisplatin-induced apoptosis via Bcl-2-modulated autophagy in laryngeal carcinoma cells Hep-2. Neoplasma. 2018;65(1):42-48. doi:10.4149/neo_2018_161102N528

32. Sun WL, LAN $\bar{D}$, GAN TQ, et al. Autophagy facilitates multidrug resistance development through inhibition of apoptosis in breast cancer cells. Neoplasma. 2015;62(2):199-208. doi:10.4149/neo_2015_025

33. Wen J, Yeo S, Wang C, et al. Autophagy inhibition re-sensitizes pulse stimulation-selected paclitaxel-resistant triple negative breast cancer cells to chemotherapy-induced apoptosis. Breast Cancer Res Treat. 2015;149(3):619-629. doi:10.1007/s10549-015-3283-9

\section{Publish your work in this journal}

Cancer Management and Research is an international, peer-reviewed open access journal focusing on cancer research and the optimal use of preventative and integrated treatment interventions to achieve improved outcomes, enhanced survival and quality of life for the cancer patient.
The manuscript management system is completely online and includes a very quick and fair peer-review system, which is all easy to use. Visit http://www.dovepress.com/testimonials.php to read real quotes from published authors. 